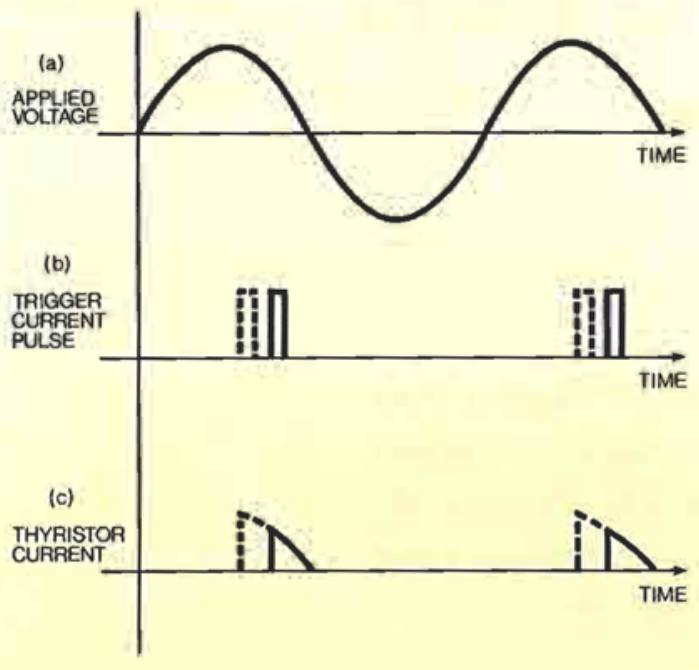

Fig. 13 Power control application of a thyristor. (a) shows the voltage applied to the device, (b) the current pulses which trigger forward conduction and (c) the resulting controlled output eurrent waveform (all to the same time scale). Note that as the trigger pulse is applied earlier (dotted outline), the mean current (dotted and full outlines) increases

of silicon wafers, $50 \mathrm{~mm}$ in diameter, after processing, together with some individual devices separated from the wafers. Figure 12 shows thyristors mounted on heat sinks, complete with wires bonded to the device terminals, before and after encapsulation in plastic.

\section{Applications of Thyristors}

Thyristors are used in the power control systems of a wide range of $\mathrm{AC}$ machines and circuits (7). The basic mechanism of operation is common to all applications and is illustrated in Figure 13. An alternating voltage is applied between the anode and the cathode of the thyristor, suitably chosen to withstand the full voltage excursion in both forward and reverse directions (Figure 13(a)). Figure 13(b) shows a series of current pulses applied to the gate electrode. These pulses can be derived from the voltage signal itself, but their phase relative to that voltage must be variable. The function of the pulses is to trigger the forward-conducting, or 'on' state of the thyristor. The current waveforms of Figure 13(c) are the resulting current flow through the thyristor, with the dotted trigger pulses of Figure 13(b) causing the dotted current waveforms, thus indicating that the earlier the triggering occurs, the greater the mean current flow.

Variable-phase operation allows thyristors to be applied directly to controlling the power input to systems such as light dimmers or electric cookers, the thermal time constant of which is much larger than one period of the AC supply. For systems that respond more rapidly, such as electric motors, it is necessary to smooth the current waveform using filter circuits, but these are simple to provide. Thyristor control of DC motors is achieved by controlling either the armature current, or the field current, or both. This can be applied to motors of almost any size, ranging from those in domestic appliances, to those for electric railway traction, and even to the very large machines which are used in modern steel rolling mills.

The range of application of thyristors in the engineering and consumer markets is almost limitless, and this potential will be increasingly realized as their performance continues to improve and their costs are reduced.

\section{References}

I B. G. Streetman, 'Solid State Electronic Devices', Prentice Hall Inc., Englewood Cliffs, N. J., 1972

2 A. S. Grove, 'Physics and Technology of Semiconductor Devices', John Wiley \& Sons Inc., New York, 1967

3 W. Shockley and W. T. Read, Phys. Rev., 1952, 87, 835-842

4 R. N. Hall, Phys. Rev., 1952, 87, 387

5 W. R. Wilcox and T. J. LaChappell, f. Appl. Phys., 1964, 35, $240-246$

6 F. A. Trumbore, Bell Syst. Tech. F., 1960, 39, 205-233

7 F.E. Gentery, F. W. Gutzwiller, N. Holonyak, Jr. and E. E. von Zastrow, 'Semiconductor Controlled Rectifiers: Principles and Applications of $p-n-p-n$ Devices', Prentice Hall Inc. Englewood Cliffs, N. J., 1964

\section{Gold-Coated Glass Retains Its Strength}

Although the effects of coatings of gold and other metals on the optical properties of glass are well documented, their influence on its mechanical properties have not been closely studied. Past studies indicate that inorganic coatings usually decrease the strength, and therefore safety, of glass, but no satisfactory explanation for this effect was available until the recent publication of work by $\mathrm{H}$. Ishikawa, $\mathrm{N}$. Shinkai and H. Sakata (7. Mater. Sci, 1980, 15, (2), 483-490) of Asahi Glass Co., Ltd., in Yokohama.

These authors used pre-flaxved samples of commercial float glass, coated with chromium, aluminium, gold or silver, and submitted them to three-point static bending tests. Chromium deposits decreased the strength by about 80 per cent and this was more pronounced as the thickness of the coatings was increased from 25 to $250 \mathrm{~nm}$. The effect is attributed to the brittleness of chromium films, their strong bonding to glass and the presence of high tensile stresses in them. Thus, cracks which develop in the metal penetrate into the glass and induce sample failure. With aluminium deposits, the loss of strength is less drastic and it is suspected that cracks are initiated by impurities possibly oxide particles - at the metal-glass interface. Gold and silver coatings, on the other hand, do not significantly affect the bending strength of glass because tensile stresses in them are low and the metal-glass bond is weak. Hence, cracks in the films do not propagate into the glass. 